\title{
WALTER BENJAMIN E A PARIS MATERIAL
}

Jorge de Freitas ${ }^{1}$

\section{RESUMO}

A proposta deste artigo é discutir alguns aspectos da modificação da estrutura material de Paris destacados por Walter Benjamin no Projeto das Passagens. Para tal, destacaremos o poema "O cisne" (Le cygne) de Charles Baudelaire e a reurbanização promovida pelo Barão de Haussmann no século XIX.

PALAVRAS-CHAVE: Paris; Benjamin; Baudelaire; Reurbanização.

\section{WALTER BENJAMIN AND THE MATERIAL PARIS}

\begin{abstract}
The purpose of this article is to discuss some aspects of the modification of the Paris structure material posted by Walter Benjamin in the Arcades Project. To this end, we will highlight the poem "The Swan" (Le cygne) Charles Baudelaire and redevelopment promoted by Baron Haussmann in the nineteenth century.
\end{abstract}

KEYWORDS: Paris; Benjamin; Baudelaire; Redevelopment.

\section{Introdução}

A metrópole de Paris surge como uma importante imagem na reflexão que Walter Benjamin constrói acerca da modernidade benjaminiana não apenas pela posição de personagem principal que ocupa na poesia de Charles Baudelaire, poeta considerado por Benjamin como expoente da modernidade, como também pela importância da cidade no cenário de consolidação do processo de produção capitalista e de seu posicionamento como metrópole do século XIX. Para Ernani Chaves, isso de dá por meio da efetivação da promessa de um "ideal” que antes de tudo "é sempre sonhado"2 através das fantasmagorias. A alegoria da metrópole pode ser compreendida através de dois aspectos fundamentais: pela interpretação da reestruturação material de Paris ocasionada pelas reformas urbanísticas do século XIX e pela constatação da criação de uma cidade de sonhos que atua no imaginário de seus habitantes. O aspecto comum dessa alegoria - que se situa na

\footnotetext{
${ }^{1}$ Doutorando em Estudos Literários (POS-LIT/FALE) pela Universidade Federal de Minas Gerais (UFMG). E-mail: defreitasjorge@yahoo.com.br

${ }^{2}$ CHAVES. Der zweite Versuch der Kunst, sich mit der Technik auseinanderzusetzen: Walter Benjamin e o Jugendstil’. In: Revista Artefilosofia, p. 61.
} 
ambiguidade entre uma constituição material e uma construção onírica - é que em ambos os casos, material e onírico, o regente das interpretações é o signo da transitoriedade dos elementos da metrópole.

Uma consideração importante sobre a regência que o signo da transitoriedade exerce na metrópole parisiense é a evidenciação da fragilidade de suas construções, algo capaz de revelar a existência de um movimento de interpenetração entre elementos da Paris antiga e da Paris moderna. Em outras palavras, a transitoriedade da Paris - tanto aquela que se constrói materialmente, como aquela que se constitui como uma esfera de sonhos - revela a interpenetração entre elementos da antiguidade e da modernidade, característica principal da modernidade benjaminiana. Como exemplo dessa interpenetração, as reformas urbanísticas do Barão de Haussmann oferecem um arquétipo privilegiado, pois no embelezamento estratégico de Paris, Haussmann, o "artista da demolição", ao levantar uma "nova Paris" deixa como rastro as ruínas de uma Paris antiga. Sem dúvida, esse movimento de destruição e construção está marcado não só pelo signo da transitoriedade, como também pela temporalidade destrutiva da modernidade, uma vez que as construções de hoje estão fadadas ao perecimento amanhã. Isto é, aquilo que é visto como novidade em breve será considerado como antigo e se tornara ruína. Nesse sentido, de acordo com Kátia Muricy no artigo "O heroísmo do presente", tudo aquilo que está ligado "à busca do novo, está paradoxalmente ligado à morte, à destruição no tempo. A cidade grande é o cenário desta morte"3. Tal movimento de reurbanização revela, também, a exclusão inerente ao embelezamento e a modernização da metrópole, pois os operários que durante o dia reformam a cidade são à noite expulsos para os subúrbios. Exclusão que é representada com maestria pelo poema "O cisne" (Le cygne), de Baudelaire.

\section{A Paris material}

Paris, a morada das fantasmagorias, entendida como uma espécie de mônada onde é possível apreender a totalidade das relações que deram forma à modernidade do século XIX, é o local escolhido por Benjamin para desvendar a historiografia material e o imaginário da sociedade moderna. A metrópole destaca-se nas observações benjaminianas por situar-se como o lugar privilegiado para o desenvolvimento das passagens, das inovações tecnológicas, da moda, da arquitetura, constructos que abrigaram e representaram o desenvolvimento pleno dos conceitos de progresso e de fetiche. Para Benjamin, a metrópole parisiense foi capaz de incorporar ao seu desenvolvimento a "forma do novo meio de produção", no qual o desfecho principal foi a

\footnotetext{
${ }^{3}$ MURICY. O heroísmo do presente. In: Tempo Social. Revista de Sociologia USP, p. 40.

${ }^{4}$ BENJAMIN. Paris, a capital do século XIX. In: Passagens, p. 41.
} 
consolidação do imaginário social dos habitantes de Paris sob a forma do culto ao progresso e à fetichização das relações sociais, ambos através das imagens de sonho. Desse modo, a metrópole francesa tornou-se, por excelência, a morada do culto ao capitalismo, culto fortalecido pelas recorrentes exposições universais, apresentadas incialmente como "lugares de peregrinação ao fetiche da mercadoria." 5

Ao entendermos a Paris moderna de Benjamin como o cenário onde as potências da modernidade encontram o amplo desenvolvimento, iremos caracterizá-la, inicialmente, como tendo o signo da transitoriedade como o seu paradigma de inteligibilidade, apresentando as modificações materiais da metrópole e seu impacto na consolidação do sujeito.

Cabe dizer, portanto, que a noção de transitoriedade se situa como o determinante de um modelo de desenvolvimento regido pelos conceitos de progresso e de fetiche, conceitos que se encontram em constante movimento, sempre apresentando novas e transitórias constituições, sempre se adaptando ao moderno jogo alegórico de significação. Já a noção de progresso pode ser ilustrada com o avanço das tecnologias de reprodução imagética. Esse movimento pode ser exemplificado com o desenvolvimento dos panoramas, técnica de reprodução imagética que, segundo Benjamin, anunciava "uma revolução nas relações da arte com a técnica". 6 Tal técnica não figurou por muito tempo como a última novidade no cenário da reprodução imagética e foi rapidamente substituída pela fotografia. Já a técnica fotográfica, por sua vez, perdeu o seu posto e foi substituída, como última moda na reprodução e captação de imagens, pelo cinema, primeiramente o mudo e posteriormente o falado. A transitoriedade, por sua vez, inerente ao conceito de fetiche, pode ser exemplificada pela moda. É fato que, nesse movimento transitório, a moda mais recente - a última novidade - exerce uma potência enfeitiçadora mais forte do que a anterior e acaba por tomar-lhe o lugar. Assim, a "fantasia impulsionada pelo novo"7 torna-se capaz de renovar a força do fascínio que a mercadoria exerce sobre os sujeitos e, devido ao seu caráter de última novidade no mercado, o movimento transitório da moda apresenta renovada a fantasia da mercadoria de colocar-se como a capacidade de realização imediata das promessas. A relação de transitoriedade estabelecida no movimento entre a permanência de elementos antigos e a iminência da novidade na constituição da metrópole parisiense pode ser entendida através da visão de uma cidade cuja estrutura material é sempre mutável. Uma cidade constantemente marcada pelas reformulações urbanísticas que removem do seu cenário as antigas construções para que essas possam ceder o seu lugar às novas, como foi o caso exemplar de Paris. Porém, as ruínas dessa destruição permanecem, visto que as "novas" construções estão fadadas ao mesmo destino das "antigas", a saber, o deperecimento, a morte. Este movimento de reurbanização que expõe a

\footnotetext{
${ }^{5}$ BENJAMIN. Paris, a capital do século XIX. In: Passagens, p. 43.

${ }^{6}$ BENJAMIN. Paris, a capital do século XIX. In: Passagens, p. 45.

${ }^{7}$ BENJAMIN. Paris, a capital do século XIX. In: Passagens, p. 41.
} 
fragilidade material da capital francesa revela não apenas a violência exercida contra os monumentos de uma Paris antiga, como também apresenta a violência exercida contra o habitante da metrópole - para o qual a cidade torna-se estranha e desumana.

Para Benjamin, a "cidade de Paris ingressou nesse século sob a forma que lhe foi dada por Haussmann. Ele realizou sua transformação da cidade com os meios mais modestos que se possa pensar: pás, enxadas, alavancas e coisas semelhantes" ${ }^{\prime 8}$. É justamente na modificação do espaço urbano da metrópole que a marca da transitoriedade de Paris revela-se com maior primazia, fundada principalmente pelas reformas urbanísticas do Barão Haussmann, iniciadas em 1859. As reformas de Haussmann visavam o embelezamento estratégico da metrópole através da substituição da "verdadeira Paris", uma cidade naturalmente "escura, lamacenta, malcheirosa, confinada em suas ruas estreitas", , por uma cidade extremamente planejada, com largas e arborizadas avenidas (boulevards), que tinham como intuito, sobretudo, impedir a insurreição dos populares em barricadas e propiciar o deslocamento mais efetivo das tropas militares, proporcionando, assim, uma nova fisionomia para a cidade. De acordo com Benjamin, ao citar um fragmento do arquivo temático "E - Haussmannização, Lutas de barricadas", o embelezamento estratégico consistiria em dois movimentos: na abertura de "Novas artérias" que "fariam comunicar o coração de Paris com as estações e as descongestionariam" e, principalmente, na abertura de outras vias que "participariam do combate travado contra a miséria e a revolução; seriam vias estratégicas, atingindo os núcleos de epidemias, os centros de rebeldia, permitindo, com a vinda de ar puro, a chegada do exército". ${ }^{10}$

A velocidade das demolições de Haussmann transforma Paris em um canteiro de obras, em um amontoado de ruínas, de modo que a desfiguração do espaço material da metrópole aflige o seu próprio habitante, ocasiona-lhe o sentimento de ser um estrangeiro em sua própria cidade. Nesse contexto, temos a seguinte afirmação de Benjamin: “Aquilo que sabemos que, em breve, já não teremos diante de nós torna-se imagem" ${ }^{11}$, isto é, o caráter transitório e mutável da imagem de Paris provoca em seus habitantes o estranhamento em relação à cidade que habitam. A fisionomia transitória de Paris, arruinada pelos intentos megalomaníacos de Haussmann, aponta para o “desprezo da experiência histórica” (BENJAMIN, 2009, p. 172, [E 5, 6]), experiência essa que o parisiense construiu anteriormente com sua cidade. Aponta também para a desvalorização dos elementos da própria cidade, incluindo-se aí o próprio habitante. Desse modo, na imagem da Paris moderna, regida pela transitoriedade e fragilidade das suas construções, a possibilidade do parisiense construir uma relação experiencial com a metrópole é impossibilitada pela volatização das construções arquitetônicas da cidade. Por isso a experiência que a Paris de Haussmann

\footnotetext{
${ }^{8}$ BENJAMIN. A modernidade. In: Obras Escolhidas III. Charles Baudelaire, um lírico no auge do capitalismo, p.84.

${ }^{9}$ BENJAMIN. P - As ruas de Paris. In: Passagens, p.564. [P 4,1].

${ }^{10}$ BENJAMIN. E - Haussmannização, Lutas de barricadas. In: Passagens, p. 169. [E 3a, 3].

${ }^{11}$ BENJAMIN. Paris, a capital do século XIX. In: Passagens, p. 49.
} 
possibilita ao seu habitante é a do estranhamento ${ }^{12}$ frente às constantes mudanças em sua estrutura, ou seja, não é, de modo algum, uma experiência enraizada no sujeito (Erfahrung), mas, sim, uma vivência (Erlebnis) que se choca com o estranhamento produzido pela transitoriedade da metrópole familiar arruinada. Benjamin evidencia o caráter destrutivo e a sensação de estranhamento da haussmannização de Paris com uma citação de Dubech e D’Espezel em Historie de Paris, como pode ser visto no seguinte fragmento:

Sobre Haussmann: "Paris deixou, para sempre de ser um conglomerado de pequenas cidades tendo a sua fisionomia, sua vida; onde se nascia, onde se morria, onde se gostava de viver, que não se pensava em abandonar; onde a natureza e a história tinham colaborado para realizar a variedade na unidade. A centralização, a megalomania criaram uma cidade artificial onde o parisiense, traço essencial, não se sente mais em casa. Assim desde que pode, ele vai embora, eis uma nova necessidade, a mania da vilegiatura. Inversamente, na cidade deserdada de seus habitantes, o estrangeiro chega com data fixa: é a 'estação'. $O$ parisiense, na cidade transforma-se em encruzilhada cosmopolita, sente-se desenraizado."13

Paris torna-se, então, estranha para o seu habitante, a antiga relação de pertencimento que o parisiense estabelecia com sua cidade não existe mais, as construções de outrora são substituídas por estruturas da metrópole haussmanizada, caracterizada como "um grande mercado de consumo, um imenso canteiro de obras, uma arena de ambições, ou apenas um ponto de encontro dos prazeres. Não é a terra deles" $" 14$. No entanto, pode-se dizer que algo de antigo permanece na constituição da "nova Paris", pois o movimento de reurbanização da cidade produz, incessantemente, ruínas. Essa produção é capaz de evidenciar que as novas construções possuem o mesmo destino das antigas, a saber, a morte, o deperecimento, a ruína. Jeane Marie Gagnebin, em Sete aulas sobre linguagem, memória e história, resume esse movimento de copertencimento entre o antigo e o novo realizado pelas reformas de Haussmann de modo muito esclarecedor:

\footnotetext{
Haussmann realiza materialmente a aproximação do antigo e do moderno pela manifestação da caducidade do presente: às minas do passado correspondem as de hoje; a morte não habita só os palácios de ontem, mas já se apoderou dos edifícios que estamos construindo. É esta convergência do passado e do presente na forma de seu futuro comum, a morte, que
}

\footnotetext{
${ }^{12}$ Podemos aproximar essa experiência do estranhamento que a modificação da estrutura de Paris proporciona ao seu habitante com a teoria de Freud em "O inquietante" (Das Unheimliche), onde ele define o aspecto inquietante como uma "espécie de coisa assustadora que remonta ao que é há muito tempo conhecido, ao bastante familiar" (FREUD, 2010, p. 331), mas que por algum motivo tornou-se estranho, inquietante. Talvez esse seria o sentimento do parisiense frente à reurbanização de Paris, um misto de horror e medo em face à modificação das ruas, casas, lojas que antes lhe eram familiares. Um sentimento de estranhamento daquilo que se fazia, no seu dia-dia, uma imagem familiar. Utilizamos para essa comparação, o ensaio "O inquietante", presenta no Décimo quarto volume das obras escolhidas de Sigmund Freud, cuja referência bibliográfica é a seguinte: FREUD, S. História de uma neurose infantil: ("O homem dos lobos”): além do princípio do prazer e outros textos (1917-1920). Trad. Paulo César de Souza. São Paulo: Companhia das letras, 2010.

${ }^{13}$ DUBECH; D’ESPEZEL apud BENJAMIN. E - Haussmannização, Lutas de barricadas. In: Passagens, p. 169. [E 3a, 6]. Grifos nossos.

${ }^{14}$ BENJAMIN. E - Haussmannização, Lutas de barricadas. In: Passagens, p. 168. [E 3a, 1]. Grifos nossos
} 
caracteriza a consciência temporal da modernidade. O sempre-novo revela-se na sua obsolescência essencial, no brilho da vida fulgura a chama da destruição. ${ }^{15}$

O movimento de transitoriedade de Paris, não revela somente o destino comum das estruturas do antigo e do moderno, revela também, por meio dos efeitos das escavações da cidade, os resíduos de uma outra Paris, uma cidade antiga, cuja linguagem que "falam as ruas e vielas incessantemente atravancadas, destruídas e refeitas, desde os primeiros dias da cidade"16 não apenas, evoca o seu lugar na construção da Paris de Haussmann, mas também reclama pelos lamentos dos seus habitantes e pelos símbolos que já não possuem lugar na estrutura mutável da cidade, conforme destaca Baudelaire nos versos do poema "O cisne".

Benjamin destaca que a fragilidade, a transitoriedade da metrópole parisiense e o movimento de interpenetração entre antiguidade e modernidade são alegorizados com primazia em "O cisne". Esse poema, segundo Benjamin, "possui o movimento de um berço que balança entre a modernidade e Antiguidade"17. Pode-se inferir, nesse sentido, que a construção do poema baudelairiano repousa nas alegorias que nos remetem à transitoriedade de Paris, construção destacada em versos:

Foi-se a velha Paris (de uma cidade a história

Depressa muda mais que um coração infiel);

$[\ldots]$

Paris muda! muda, mas nada em minha nostalgia

Mudou! novos palácios, andaimes, lajedos,

Velhos subúrbios, tudo em mim é alegoria.

E essas velhas lembranças pesam mais do que rochedos. ${ }^{18}$

Versos nos quais, de acordo com Gagnebin, está tematizado o "processo de corrosão do tempo que caracteriza a consciência da modernidade" ${ }^{19}$, consciência determinada pela constatação do signo da transitoriedade que transforma o novo em ruína e decreta - como visto anteriormente o destino comum às estruturas inorgânicas ou orgânicas da metrópole: o deperecimento. Nesse sentido, tanto a imagem da cidade que muda em uma velocidade assustadora, quanto as alegorias dos exilados presentes no poema - depositadas, sobretudo, nas imagens do cisne, de Andrômaca e da negra, entendidos como imagens de uma Paris fragilizada - têm a sua estrutura moldada como "símbolos de fragilidade". Enquanto estruturas orgânicas, esses exilados são entendidos em duas vertentes: a) como "símbolos de criaturas vivas (a negra e o cisne)" e b) como "símbolos históricos (Andrômaca, 'viúva de Heitor e... mulher de Heleno')"20. Entretanto, em ambos os símbolos o

\footnotetext{
${ }^{15}$ GAGNEBIN. Sete aulas sobre linguagem, memória e história, p.150.

${ }^{16}$ BENJAMIN. C - Paris antiga, catacumbas, demolições, declínio de Paris. In: Passagens, p. 136. [C 7a,1].

${ }^{17}$ BENJAMIN. J - Baudelaire. In: Passagens, p.402. [J 72,5].

${ }^{18}$ BAUDELAIRE. O cisne. In: As flores do mal, p. 301-303.

${ }^{19}$ GAGNEBIN. Sete aulas sobre linguagem, memória e história, p.151.

${ }^{20}$ BENJAMIN. A modernidade. In: Obras Escolhidas III. Charles Baudelaire, um lírico no auge do capitalismo, p.81.
} 
entendimento comum é que eles simbolizam uma relação com a tradição que já não possui mais local na sociedade moderna - em suma, representam a exclusão de uma tradição no seio da modernidade. Nesse sentido, o traço comum a esses símbolos - orgânicos ou históricos -, "é a desolação e desesperança pelo que virá". ${ }^{21}$

Os símbolos da fragilidade da metrópole - fragilidade orgânica (o cisne e a negra) e histórica (Andrômaca) - significam, para Luciano Gatti, no artigo "Experiência da Transitoriedade: Walter Benjamin e a modernidade de Baudelaire", "a expulsão da vida orgânica pelo processo de urbanização e transformação em concerto de todo o ambiente"22 e a consolidação do "exílio de uma tradição histórica e literária". Desse modo, a estruturação transitória da Paris do século XIX determina que qualquer perspectiva de futuro para os exilados está, de antemão, fadada a tornar-se um amontoado de ruínas.

No poema "O cisne", "Baudelaire faz o registro do exílio no interior de uma Paris em reconstrução sob os auspícios do projeto de reurbanização efetuado pelo Barão Haussmann"23, afirma Gatti. Nesse sentido, o sentimento de exílio se faz presente na imagem do poeta que lamenta perante a violência da destruição e o não reconhecimento de sua antiga cidade. Baudelaire é um exilado - tal como o cisne e Andrômaca - e que está inserido no jogo de transitoriedade dos símbolos da cidade parisiense. Todavia, sua situação é ainda mais desesperadora, pois ele tem ciência que na força desse processo de reurbanização, capaz de revelar a fragilidade material e imaterial da metrópole parisiense, repousa a possibilidade - fundada, sobretudo, na crença de um progresso infinito da técnica e da ciência - de que, com apenas um golpe, a cidade é feita em ruínas. É nesse sentido que Gatti afirma que

Alguns testemunhos, que Benjamin recolhe na sua afinidade com o projeto de Baudelaire de revelar a antiguidade no interior da modernidade, revelam o pressentimento de uma ameaça que paira sobre a cidade moderna e que poderia, de um golpe, reduzi-la em ruínas comparáveis àquelas que transformaram as cidades antigas. ${ }^{24}$

Nesse conjunto de testemunhos destaca-se a visão "de que, juntamente com as grandes cidades, cresciam os meios que permitem arrasá-las" ${ }^{25}$. Entre esses testemunhos, Benjamin destaca as colocações do escritor Maxime du Camp e as representações do gravurista francês Charles Meryon, o primeiro acreditando que a cidade está fadada à "lei inevitável da caducidade de todas as

\footnotetext{
${ }^{21}$ BENJAMIN. A modernidade. In: Obras Escolhidas III. Charles Baudelaire, um lírico no auge do capitalismo, p.81.

${ }^{22}$ GATTI. Experiência da Transitoriedade: Walter Benjamin e a modernidade de Baudelaire. In: Revista Kriterion, p. 168 .

${ }^{23}$ GATTI. Experiência da Transitoriedade: Walter Benjamin e a modernidade de Baudelaire. In: Revista Kriterion, p. 165-166.

${ }^{24}$ GATTI. Experiência da Transitoriedade: Walter Benjamin e a modernidade de Baudelaire. In: Revista Kriterion, p.170-171.

${ }^{25}$ GEOFREY apud BENJAMIN. C - Paris antiga, catacumbas, demolições, declínio de Paris. In: Passagens, $135-136$. [C 7a,1].
} 
coisas humanas" e o segundo representando a cidade de Paris como "um campo de ruínas"26. Meryon, definido por Benjamin como um pintor alegórico, apresenta em suas gravuras sobre Paris,

\begin{abstract}
uma aparência de vida passada, que está morta ou que vai morrer... [...] ele certamente advinha que essas formas tão rígidas eram efêmeras, que essas curiosas belezas pereceriam como tudo o mais. Ele escutava a linguagem que falam as ruas e as vielas incessantemente atravancadas, destruídas e refeitas, desde os primeiros dias da cidade, e por isso sua poesia evocadora se encontra com a Idade Média através da cidade do século XIX; através da visão das aparências imediatas ele identifica a melancolia de sempre. ${ }^{27}$
\end{abstract}

São esses os sentidos que Meryon coloca em sua obra que o faz ser tão admirado por Baudelaire. O gravurista, em suas representações de Paris, condensa aquilo que o poeta, ciente da constituição transitória de Paris, quis inserir em sua obra. Pode-se dizer, nesse sentido, que a poesia urbana de Baudelaire inunda-se dos elementos que Meryon trouxe à tona ao apresentar as coisas em seu destino natural de perecimento, em sua estrutura efêmera e, especialmente, na representação da cidade moderna em sua conexão com elementos da cidade antiga - as ruínas. Se na modernidade, "Meryon fez brotar a imagem antiga da cidade sem desprezar um paralelepípedo"28, Baudelaire, continuamente em sua poesia, procurou se entregar a essa mesma ideia. Ademais, em ambos "se manifesta continuamente a forma dessa superposição, que é a alegoria" ${ }^{29}$. Por isso é evidente que em Baudelaire e em Meryon a única possibilidade de pôr-se de frente à transitoriedade estrutural da metrópole, seja ela ocasionada pelas reurbanizações promovidas por Haussmann, pelo efeito de estranhamento que provoca no habitante da metrópole ou pela visão de um declínio imediato da cidade, é por meio da inserção no jogo de significação alegórico, buscando, por fim, compreender que as antigas construções conceituais passíveis de imputar um significado único e imutável às relações construídas, não somente entre os sujeitos, mas também, entre os sujeitos e os objetos, perdem a sua validade na transitoriedade da vida moderna. Esse fator confere à metrópole moderna a determinação de uma estrutura mutável, de algo que não pode ser entendido em uma estrutura rígida e imutável e, por fim, de algo que se encontra em si mesmo inserido no mesmo processo que é imposto à mercadoria enquanto a mais recente novidade, ou seja, o destino do perecimento.

\title{
REFERÊNCIAS
}

BAUDELAIRE, Charles. O cisne. In: As Flores do Mal. Trad. Ivan Junqueira. Rio de Janeiro. Nova Fronteira, 2006.

\footnotetext{
${ }^{26}$ BENJAMIN. A modernidade. In: Obras Escolhidas III. Charles Baudelaire, um lírico no auge do capitalismo, p.8486.

${ }^{27}$ GEFFROY apud BENJAMIN. C - Paris antiga, catacumbas, demolições, declínio de Paris. In: Passagens, p. 135136. [C 7a, 1].

${ }^{28}$ BENJAMIN. A modernidade. In: Obras Escolhidas III. Charles Baudelaire, um lírico no auge do capitalismo, p.85.

${ }^{29}$ BENJAMIN. A modernidade. In: Obras Escolhidas III. Charles Baudelaire, um lírico no auge do capitalismo, p.86.
} 
BENJAMIN, Walter. Paris, capital do século XIX. In: Passagens. Trad. Irene Aron e Cleonice Paes Barreto Mourão. Belo Horizonte: Ed. UFMG; São Paulo: Imprensa Oficial do Estado de São Paulo, 2009.

. C - Paris antiga, catacumbas, demolições, declínio de Paris. In: Passagens. Trad. Irene Aron e Cleonice Paes Barreto Mourão. Belo Horizonte: Ed. UFMG; São Paulo: Imprensa Oficial do Estado de São Paulo, 2009.

. E - Haussmannização, Lutas de barricadas. In: Passagens. Trad. Irene Aron e Cleonice Paes Barreto Mourão. Belo Horizonte: Ed. UFMG; São Paulo: Imprensa Oficial do Estado de São Paulo, 2009.

J - Baudelaire. In: Passagens. Trad. Irene Aron e Cleonice Paes Barreto Mourão. Belo Horizonte: Ed. UFMG; São Paulo: Imprensa Oficial do Estado de São Paulo, 2009.

P - As ruas de Paris. In: Passagens. Trad. Irene Aron e Cleonice Paes Barreto Mourão. Belo Horizonte: Ed. UFMG; São Paulo: Imprensa Oficial do Estado de São Paulo, 2009.

A modernidade. In: Obras Escolhidas III. Charles Baudelaire, um lírico no auge do capitalismo. Trad. José Carlos Martins Barbosa e Hemerson Alves Baptista. São Paulo: Brasiliense, 1989.

CHAVES, Ernani. Der zweite Versuch der Knust, sich mit der Techink auseinanderzusetzen: Walter Benjamin e o Jugendstil’. In: Revista Artefilosofia, vol. 06, p. 56-62. Ouro Preto: ED. UFOP, $1^{\circ}$ semestre de 2009.

GATTI, Luciano Ferreira. Experiência da Transitoriedade: Walter Benjamin e a Modernidade de Baudelaire. In: Revista Kriterion, vol. 119, p. 159-178. Belo Horizonte, jun de 2009.

FREUD, Sigmund. História de uma neurose infantil: (“O homem dos lobos"): além do princípio do prazer e outros textos (1917-1920). Trad. Paulo César de Souza. São Paulo: Companhia das letras, 2010.

GAGNEBIN, Jeanne Marie. Sete aulas sobre Linguagem, Memória e História. Rio de Janeiro: Ed. Imago, 1997.

MURICY, Katia. O heroísmo do presente. In: Tempo Social. Revista de Sociologia USP. São Paulo: vol. 07, p. 31-44, out de 1995. 